\title{
SOME MEDICAL ASPECTS OF COUNTER REVOLUTIONARY WAR
}

Brigadier E. H. P. LASSEN, D.S.O., Q.H.P., M.R.C.S., D.D.M.S., 17 Division/Malaya District*

\section{Introduction}

Revolutionary War has come to be regarded as the Communist-inspired action taken by rebel insurgents against established governments in developing countries, particularly of South East Asia, and conducted by political and economic as well as military means. Guerilla activity is a predominant feature of the military methods adopted, and it is particularly difficult to counter because of the nature of the terrain and the poor communications usually obtaining.

For any lasting degree of success to be achieved it is necessary that the forces supporting the government are so trained and adapted as to be able to compete with the adverse environment, and take on the enemy on their own ground. It is also essential that the civilian population is protected from insurgent pressures and from reprisals for assisting government forces. Not only must their lives be protected, but also their means of livelihood. Their hearts and minds must be won over and only then can the insurgent cause be truly said to be defeated.

Such measures are the stuff of counter revolutionary war, and were the subject of a series of exercises and studies conducted by 17 Division in conjunction with the Royal Navy and the Royal Air Force in Malaya. These studies were not completed when the writer vacated his appointment in March 1967, but as a result of the lessons learnt from them, the following notes were issued within 17 Division, which may be of more general interest.

The medical aspects of counter revolutionary war may be considered under three headings:

Prevention of disease, and health discipline.

Treatment and evacuation of sick and wounded.

Assistance to the civilian population-hearts and minds.

\section{Prevention of disease, and health discipline}

There are no new lessons to be learnt, but the old ones can only be disregarded at one's peril; the conditions in which soldiers are required to live and fight are adverse, and demand of all ranks not only a high degree of physical fitness and mental robustness, but also the strictest observance of all hygiene precautions. Without physical and mental stamina, without a full appreciation and application of the various health disciplines, the hazards to health are such that the fighting efficiency of a force would be seriously impaired through avoidable ill health and sickness.

The responsibility for the health of the troops lies with commanders at all levels, acting upon medical advice, and the importance of hygiene and health discipline has

^ Now: D.D.M.S., H.Q., Northern Command. 
been appreciated by commanders under active service conditions over the years. It is equally true to say that these disciplines tend to be neglected in peace, when hygiene seems to be of less importance, and then forgotten in war. The enormous number of casualties from malaria and dysentery in the early part of the Burma campaign of World War II, and more recently the high sickness rate during the Suez crisis, underline the fact that the established lessons and disciplines still have to be re-learnt through the bitter experience of war.

In order to promote and maintain health and prevent disease every aspect of the soldier's life and environment must be considered. Attention must be paid to food, its preparation and protection, sanitation and water supplies, clothing and personal cleanliness, rest and acclimatisation, as well as measures against specific disease such as malaria, dysentery, cholera, scrub typhus and leptospirosis. Detailed recommendations are laid down in 17 Division Standing Instructions for Operations; the pamphlet 'Your Health and You' should be required reading for individual soldiers, and the Handbook of Army Health for regimental officers.

In counter-revolutionary war it is envisaged that troops may be deployed in isolated groups, moving on foot and operating independently, possibly for considerable periods, with irregular communication with their unit headquarters and the main forces. In these circumstances the need for self sufficiency is evident; and unless hygiene measures and disciplines are learnt, fully appreciated, and instinctively carried out whatever the conditions, loss of fighting efficiency and a high wastage rate through preventable sickness is inevitable.

\section{Treatment and evacuation of casualties}

The treatment and evacuation of the sick and wounded is the responsibility of the medical services, but evacuation by road has increasingly been superceded by air transportation. The great advantage of air evacuation is the shortening of the time factor, and the speed with which casualties can be got to the Casualty Clearing Station (CCS) for definitive surgical treatment. The disadvantage is that direct control of the means of evacuation has been removed from the medical services, aircraft being under control of the staff to whom application for air evacuation must be made, and medical bids must compete with other operational requirements.

In conditions of counter-revolutionary war, distance, the condition of the roads, if any, as well as the threat of enemy infiltration make evacuation by road hazardous and in many instances impossible. Evacuation by air is therefore to be regarded as normal, and road evacuation would be resorted to only if and when conditions for it were acceptable, and air evacuation precluded by bad weather or enemy interdiction.

Air transportation and the shortening of the time factor in the evacuation of casualties from the forward area to the CCS demand a revision of the forward medical organisation. The need for intermediate medical aid stations is lessened and their numbers will depend upon distances and the range of aircraft involved. Medical units and sub-units must be sited in relation to airstrips and landing zones, as a check on the condition of casualties will always be required when an aircraft lands. The deployment of the forward medical organisation must be adaptable to meet any conditions; superfluous and intermediate medical staging posts should be avoided and the aim must be the speediest evacuation of casualties consistent with the maintenance of their optimum condition. 


\section{Direct air evacuation-within the brigade area}

\section{Field ambulance company}

Evacuation of casualties is effected by helicopter from a point nearest to where the casualty occurred, consistent with the safety of the aircraft, usually a landing zone at infantry company headquarters. Thence the casualty may be flown direct to the Advanced Dressing Station (ADS) there being no need to make an intermediate halt at battalion headquarters for further first aid treatment by the Regimental Medical Officer (RMO).

The field ambulance company role of evacuation of casualties to the ADS has thus been taken over by the Royal Air Force, but its treatment role remains. This treatment is now being carried out at infantry company level and not at the battalion regimental aid post, or intermediately. It is therefore logical to consider the deployment of a field ambulance section, or part thereof, with infantry companies where it will be in a position materially to assist the regimental orderlies in first aid treatment. A role as medical escorts to seriously wounded casualties being flown to the ADS is also appropriate, and they should be so employed when necessary.

Interdiction of flying by weather or enemy action is a contingency which must always be borne in mind and when this occurs, with evacuation by road being impracticable, casualties will perforce have to be held in company or other positions in the forward area until the situation is restored and flying is once more possible. This lends added force to the deployment of field ambulance personnel within the battalion so that skilled supportive treatment is made available to casualties, and their condition maintained as well as possible.

For similar reasons it is also important that all ranks of all arms are skilled in first aid. Any patrol may find itself cut off, and, sustaining casualties, will be required to hold and treat them until evacuation can be effected, which may not be possible for many hours. The need for the continuous training of all ranks in the basic principles of first aid must therefore receive a high priority.

\section{The regimental medical officer}

The position of the RMO needs to be considered. In the circumstances described above of evacuation by air from company areas to the ADS direct, the RMO in the Regimental Aid Post (RAP) at Battalion headquarters is isolated. His own unit's casualties in the forward areas will overfly him, and he can only be of use to any sick or wounded occurring within the battalion headquarters perimeter. Such casualties are not likely to be greater than those occurring in any company position, and there is therefore no particular justification for retaining the RMO at the Regimental Aid Post in these circumstances.

The RMO's role in battle is to render doctor first aid to casualties; this he no longer can do at the RAP, but he could be deployed at company level from where the casualties are being despatched, or in the ADS where they are being received and treated. Placing the RMO in a company is not recommended except in unusual circumstances (e.g. large numbers of wounded requiring skilled medical attention, and evacuation being impossible) but usually such positioning of the RMO would be wasteful and ineffectual. There is however, every reason for putting him temporarily in the ADS, where in the height of battle, the field ambulance is always hard pressed, and additional medical officer 
assistance would be invaluable. There, the RMOs would be treating their own unit and other brigade casualties impartially, speeding up the rate at which they could be transferred to the CCS.

There are liable to be objections from commanding officers and others to such a proposal but it should be appreciated that battalions are not being deprived of their RMOs, but only that they are being positioned where they can most effectively discharge their role of the treatment of unit casualties. It is no valid argument to say that in the event of air evacuation being interrupted, the RMO would be cut off from his battalion if located in the ADS, since with road evacuation being impracticable, he would be equally inaccessible to casualties occurring in the forward companies even if he remained in the RAP.

If his presence were more urgently required elsewhere, the RMO would be sent back to his RAP or elsewhere as the situation demanded. Thus in an extended deployment of a battalion with a relatively long distance between company and battalion headquarters, an intermediate staging of the casualty at RAP level might be indicated. In such a case the obvious place for the RMO would be in his battalion RAP. Rearward evacuation from there might be direct to CCS, but there might be a further intermediate staging at the ADS. The course to be adopted would depend on the distances involved, and the range of the aircraft employed. The deployment of RMOs would be the responsibility of the commander on the advice of the Senior Medical Officer (SMO) of the brigade.

\section{The senior medical officer of the brigade}

The SMO is responsible for the medical arrangements within the brigade area. In normal circumstances he informs himself of the battle situation by constant visits to the brigade headquarters, units and RMOs, and he effects such visits by landrover. This mode of communication is impossible, where physical conditions, distances and enemy action make movement by road impracticable. He may be able to effect some communication by wireless, particularly if the intention to establish a separate medical net is implemented, but this means will never be an adequate substitute for personal liaison. If this is to continue, means of air transportation must be put at his disposal, and while it is unlikely that the permanent allocation of a helicopter to the field ambulance could be contemplated, consideration should be given to a temporary allocation when aircraft can be spared from other essential duty. If this facility is not afforded to the SMO from time to time he will cease to be able to co-ordinate, and influence the medical arrangements as changing battle situations may demand; he will remain a prisoner in his ADS unable effectively to discharge his responsibilities to his brigade commander.

\section{The field ambulance}

\section{Equipment}

In conditions of counter revolutionary war, less and less reliance can be placed on movement by. road vehicles, and consequently equipment must be reduced to a minimum. All equipment must be made of the lightest materials possible to save air freight and recommendations to this end must continue to be made, but of more immediate practical value, equipment scales must be ruthlessly pruned so that, particularly within the company of a field ambulance, mobility may be maintained under all corditions. 
In certain circumstances fighting troops will be equipped to a basic 'marching scale' in which only the barest essentials are included and are carried in man pack loads; only at a later stage may these basic scales be augmented by additional equipment brought in by air, or by road vehicles. The field ambulance company must be prepared to accompany troops on a 'marching scale' and to carry out full supportive treatment of casualties on a man pack basis.

\section{Headquarters}

The field ambulance must be flown into the Brigade Forward Operational Base early in order to provide support. The whole field ambulance headquarters is not necessary to form an effective ADS in the early stages, and with aircraft space always being at a premium only essential men and equipment are to be flown in at that time, while the remainder, e.g. the quartermaster, transport and other less essential departments, must wait to be flown in on later serials.

\section{Role of the ADS with battalions at rest}

After sorties lasting up to several weeks on jungle operations, battalions will be brought into protected camps for rest and recuperation. In these circumstances the facilities at the ADS must be of a high standard. If permanent or semi-permanent accommodation is available it should be used in preference to tentage, and short term sick must be treated under the best conditions obtainable. The field ambulance will thereby perform an invaluable service in maintaining the fighting strength of units, and prevent the further evacuation of men with consequent loss to their units for a longer period of time. To discharge this commitment adequately there is little doubt that the full scale of equipment will be required by the field ambulance.

\section{Re-supply}

Re-supply of medical equipment and stores from the Forward Maintenance Area to field ambulance is by standard 'bricks' without demand, but a problem exists in the re-supply of RAPs and medical detachments of the field ambulance company. This used to be effected quite simply by returning ambulance cars/stretcher landrovers from the field ambulance, but with air evacuation the problem is more complicated, since the same aircraft which brought casualties from forward company positions will not necessarily return there immediately, if at all.

The demands for the re-supply of medical equipment and stretchers must be met by the medical unit receiving the casualty, and despatched to the unit or sub-unit concerned by air. If this is not most carefully watched company aid posts will quickly run short of medical supplies in battle.

\section{The advanced surgical centre}

Although the attachment of 'a field surgical team to a field ambulance is not exclusively relevant to counter revolutionary war, the exercises and studies carried out to date have included such a plan.

It may therefore be useful to emphasise that the establishment of an advanced surgical centre is to be regarded as a departure from the normal medical organisation. The object underlying the forward field medical organisation is to effect the most rapid 
and efficient transfer of casualties to a medical unit where definitive surgery can be undertaken. This is normally the CCS located in the Forwarded Maintenance Area. There, in conditions of comparative quiet and free from enemy interference, with skilled medical and nursing facilities, casualties are operated upon under the best conditions obtaining in the field. The establishment of an advanced surgical centre at a field ambulance, while at times a necessity, is at best a compromise, forced upon us by the inability to evacuate casualties from the forward area, or because the time/distance factor to the CCS has become so great that the chances of the casualties' recovery are prejudiced. The advanced surgical centre's role is to perform life saving emergency surgery, but the conditions under which the surgeons operate are far from ideal and a field ambulance has neither the numbers nor the specially qualified nursing orderlies necessary for pre and post operative care.

Furthermore, the ADS would be immobilised for some 10 days after major surgery has been performed there, as many cases cannot safely be moved within that time. It is therefore clear that the-position of the ADS and hence the Forward Operational Base and the brigade commander's plan as a whole, may be prejudiced by the establishment of an advanced surgical centre within the brigade area of operations.

\section{Aid to civilian population-" hearts and minds"}

The importance of this subject in counter revolutionary war requires no emphasising, and the good work done by R.A.M.C. and non-medical personnel in operational theatres in the Far East Command has paid vast dividends, and has gone far to win the people from Communist aims and insurgent methods.

A great deal of this work has been on an 'ad hoc' basis, and medical officers and others have done what they can as the opportunity arises, using the medical supplies intended for our own forces. When casualties are light, and re-supply freely available, such help is satisfactory to the limited extent to which it goes. When conditions are adverse, hard decisions will have to be made as to what treatment can be afforded to the civilian population. It is obvious that the first priority must always be given to our own forces, and it must be appreciated that the military medical resources are geared to this end alone; they are quite insufficient to take on the enormous medical problem that the civilian population is likely to present, or to make any significant impact upon it.

The extent and scope of the aid to be given to the civilian population needs to be planned at a high level, and resources provided accordingly: without such planning and direction there is always the danger that the limited military medical resources will be diverted to the detriment of our own troops. 